Environmental Molecular Sciences Laboratory

EMSL

Pore Scale Modeling Challenge/Workshop
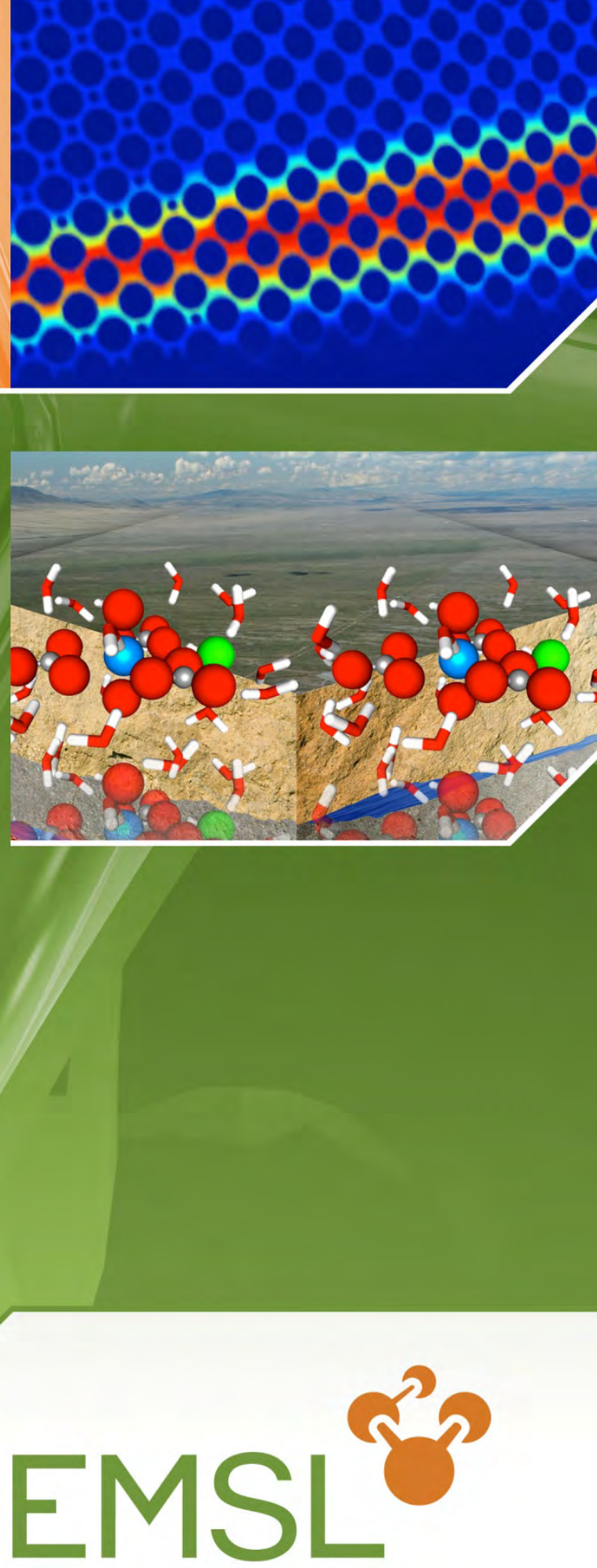


\title{
DISCLAIMER
}

This report was prepared as an account of work sponsored by an agency of the United States Government. Neither the United States Government nor any agency thereof, nor Battelle Memorial Institute, nor any of their employees, makes any warranty, express or implied, or assumes any legal liability or responsibility for the accuracy, completeness, or usefulness of any information, apparatus, product, or process disclosed, or represents that its use would not infringe privately owned rights. Reference herein to any specific commercial product. process, or senvice by trade name, trademark, manufacturer, or otherwise does not necessarily constitute or imply its endorsement, recommendation, or favoring by the United States Government or any agency thereof, or Battelle Memorial Institute. The views and opinions of authors expressed herein do not necessarily state or reflect those of the United States Government or any agency thereof.

\author{
PACIFIC NORTHWEST NATIONAL LABORATORY \\ operated by \\ BATTELLE \\ for the \\ UNITED STATES DEPARTMENT OF ENERGY \\ under Contract DE-ACO5-76RL01830 \\ Printed in the United States of America \\ Available to DOE and DOE contractors from the \\ Office of Scientific and Technical Information. \\ P.O. Box 62, Oak Ridge, TN 37831-0062; \\ ph: (865) 576-8401 \\ fax: $(865) 576-5728$ \\ enail: reportsandonis.osti.gov \\ Available to the public from the National Technical Information Service \\ 5301 Shawnee Rd, Alexandria, VA 22312 \\ ph: (800) 553-NTIS (6847) \\ email: ordersantis.gov <http://www.ntis.gov/about/form.aspx> \\ Online ordering: http://www.ntis.gov
}

This document was printed on recycled paper. 
PNNL-21086

\section{EMSL Pore Scale Modeling Challenge/Workshop}

August 9-10, 2011

Prepared for the U.S. Department of Energy's Office of Biological and Environmental Research under Contract DE-AC05-76RL01830

Pacific Northwest National Laboratory

Richland, Washington 99352 


\section{Executive Summary}

The design and implementation of cost-effective remediation strategies for subsurface contamination not only relies on descriptive models of contaminant distribution but predictive models of contaminant fate and transport. The development of such predictive models is of great importance to many government agencies including the Department of Energy (DOE), Department of Defense, and the Environmental Protection Agency. Accurate prediction of the fate and transport of environmental contaminants in the subsurface has driven development of increasingly sophisticated subsurface flow

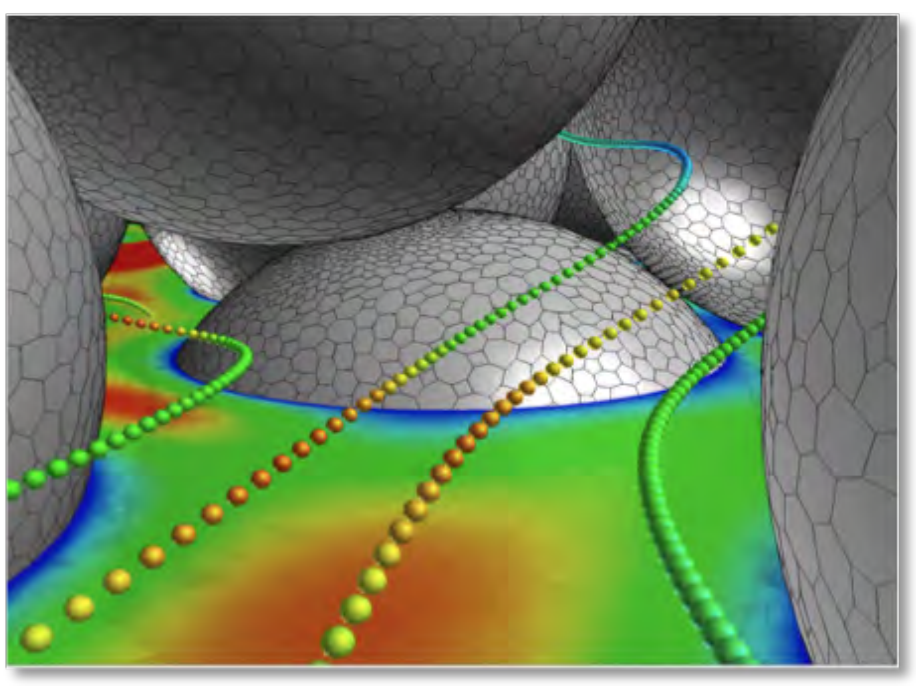

Graphical Representation of Flow and Particle Velocity (Courtesy of Marshall Richmond, PNNL)

and transport models. Even without considering spatial and temporal scalability, contaminant transport at the field scale is complex, and this almost inevitably results in an especially sophisticated model being developed for a specific field site. Unfortunately, these models are not easily generalizable to other field sites or and can only be used by the model authors to generate meaningful results. Over time, this results in the existence of numerous specialized models that are not readily comparable to each other and difficult to cross-validate. There is a lack of fundamental experimental observations at the pore scale that can be used to support model development and validation at the field scale.

The Environmental Molecular Sciences Laboratory (EMSL), located at Pacific Northwest National Laboratory (PNNL), is a national user facility that provides cuttingedge analysis tools and advanced computation, data processing, and storage and modeling capabilities. In the last five years, EMSL has developed unique pore scale fabrication and experimental capabilities. Working in collaboration of with PNNL scientists and EMSL users, EMSL has demonstrated scientific leadership in pore-scale experiments and modeling efforts. In discussions with leaders from among the pore-scale community, EMSL leadership recognized its ability to engage the larger community to accelerate scientific understanding of pore-scale phenomena, leading to the development of improved predictive models of contaminant transport at the field scale. A workshop was held in August 2011 at EMSL to identify the specific gaps in experimental data sets and modeling challenges at the pore scale that are essential for predicting diverse field-scale phenomena, such as contaminant and colloid transport, multiphase fluid displacement, mineralizing reactions, bioremediation, and deep geologic sequestration of $\mathrm{CO}_{2}$. Mart Oostrom (PNNL) and Nancy Hess (EMSL-PNNL) organized the workshop. The names of presenters, discussion leaders, and participants can be found within the appendices of this document.

Forty participants from 14 institutions, including nine invited speakers representing both the experimental and modeling communities, discussed research challenges that impede progress in the development of predictive models. They identified two major research areas where fundamental experimental data sets are needed to advance modeling and simulation. They also endorsed a new paradigm for how experimental data generated at EMSL could be shared with the modeling community that would greatly facilitate model development and validation. Recommendations were made to focus the initial experimental data sets on two pore-scale areas: 1) transverse fluid mixing and 2) fluid displacement. These areas have broad impact in nearly all field-scale predictive models of contaminant fate and transport. Workshop participants noted that maintaining sets of experimental data available to the modeling community to test and validate their models would be well positioned to result in greater understanding of different approaches for major scientific and technological impacts. Other important points addressed by the workshop participants included: 
- Existing experimental data often suffered from experimental artifacts, unknown measured errors, and undemonstrated repeatability. Many experiments failed to limit variables that could impact the resulting observations.

- EMSL has the ability to provide both expertise and tools for development of pore-scale experimental data sets not available at most universities or other national laboratories.

- Community-based development of experimental databases, visualization and simulation comparison tools, and community networking tools can provide a means for the pore-scale community to focus its resources on knowledge and technological gaps in a meaningful way.

- Collaboration within the pore-scale modeling community would create unique opportunities where coordinated and focused effort could deliver impactful results. 


\section{Acronyms and Abbreviations}

$\begin{array}{ll}\text { DOE } & \text { U.S. Department of Energy } \\ \text { EMSL } & \text { Environmental Molecular Sciences Laboratory } \\ \text { LBM } & \text { lattice Boltzmann modeling } \\ \text { MRI } & \text { magnetic resonance imaging } \\ \text { NAPL } & \text { nonaqueous phase liquid(s) } \\ \text { SPH } & \text { smoothed particle hydrodynamics } \\ \text { PNNL } & \text { Pacific Northwest National Laboratory } \\ \text { STOMP } & \text { Subsurface Transport Over Multiple Phases } \\ \text { UV } & \text { ultraviolet } \\ \text { XCT } & \text { X-ray computed tomography } \\ \text { 2D } & \text { two-dimensional } \\ \text { 3D } & \text { three-dimensional }\end{array}$




\section{Contents}

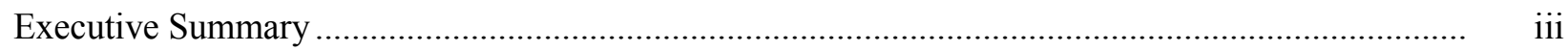

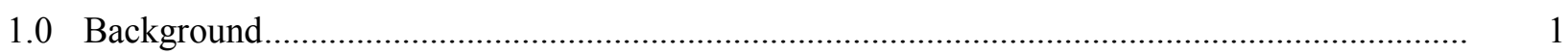

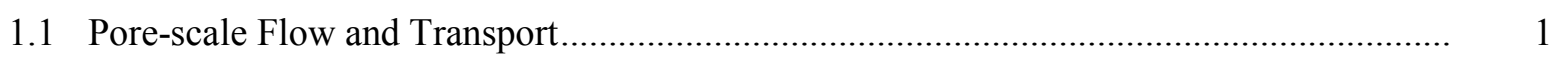

1.2 Environmental Molecular Sciences Laboratory ............................................................... 3

1.3 EMSL Pore-scale Capabilities............................................................................... 3

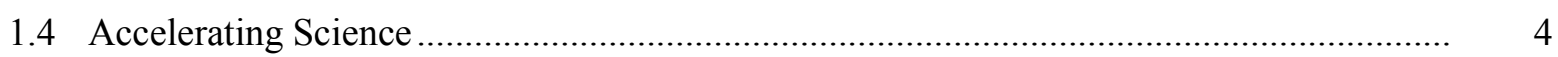

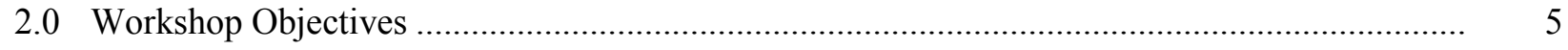

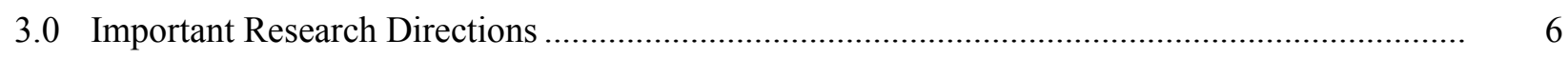

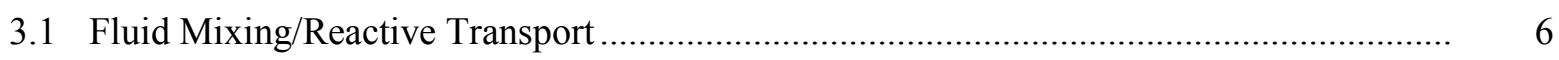

3.2 Multiphase Flow/Fluid Displacement Phenomena....................................................... 7

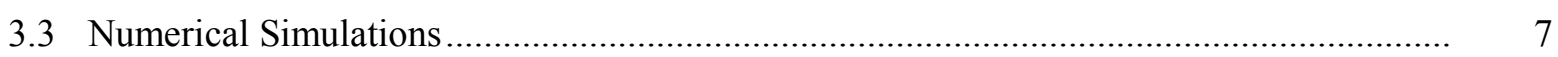

3.4 Other Opportunities for Advancing Fundamental Understanding .................................. 9

4.0 Necessary Capabilities.................................................................................................. 10

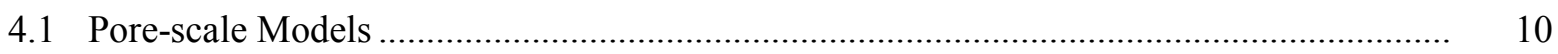

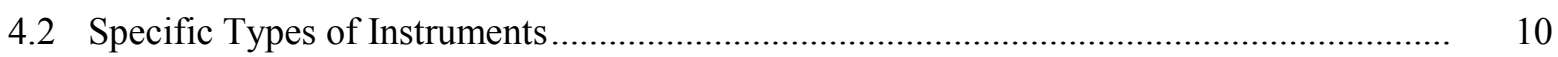

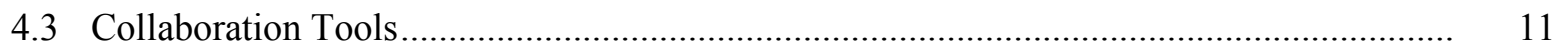

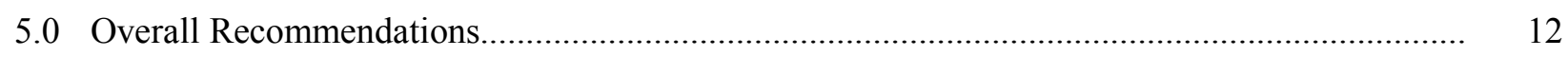

Focus on fluid mixing and fluid displacement experiments ............................................... 12

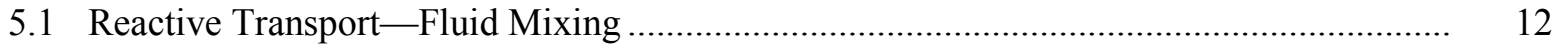

5.2 Displacement —Multiphase Flow ........................................................................... 13

5.3 Role for EMSL in Pore-scale Modeling and Team Research Success.............................. 13

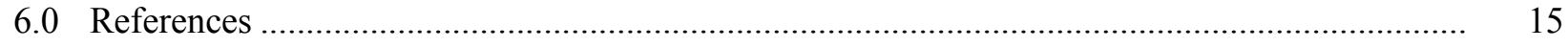

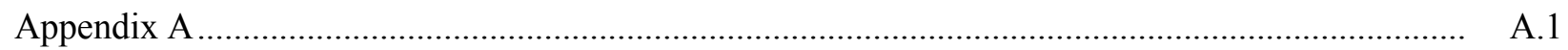

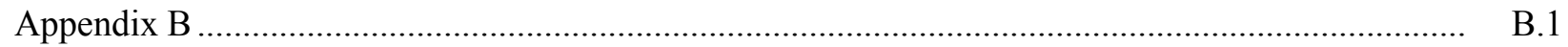

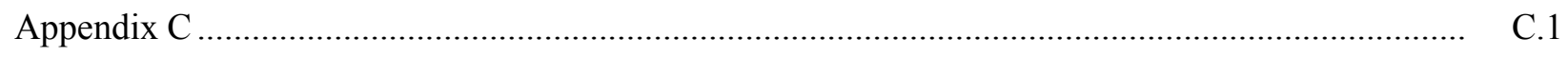

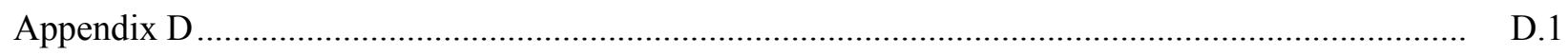




\section{Figures}

1. Pore-scale model etched in silicon. This example is designed for fluid mixing experiments with two inlets and a single outlet. The pore structure in the central region has reduced porosity to test the impact on the extent of transverse mixing.

2. Zoomed-in view of a 3D visualization of pore-scale fluid flow computed using the parallel smoothed particle hydrodynamics code (Palmer et al. 2010).

3. Flow paths in Hanford sediment core using Tethys (Transient Energy Transport Hydrodynamic Simulator) at two time points.

4. Representation of LBM volume (left) and example of trace flow using PFLOTRAN (right). From www.esd.lbl.gov/research/projects/ersp/generalinfo/modeling.html. 


\subsection{Background}

\subsection{Pore-scale Flow and Transport}

In the past decade, the development of field-scale predictive models of contaminant fate and transport has made exciting progress. Much of that progress results from greater understanding of the complexity of subsurface phenomena (DOE 2010) and the insights from new experimental and computational tools that provide molecular-level understanding of subsurface geochemistry and biogeochemistry. Increasingly, the expectation for models of contaminant transport in the subsurface is that they not only will offer accurate description of field observations but also have validated predictive capability. This expectation is held both by policy makers and remediation engineers, as well as research funding agencies. Even without considering spatial and temporal scalability, modeling contaminant transport at the field scale is complex and results in very sophisticated models being developed for specific field sites. Unfortunately, these models are not easily generalizable to other field sites or can only be used by the model developers to generate meaningful results. Over time, this results in the existence of numerous specialized models that are not readily comparable to each other and difficult to cross-validate.

Phenomena observed at the field scale, such as contaminant or tracer arrival times at fixed locations, are controlled by processes at the molecular and pore scales, including contaminant absorption and reaction, porosity, pore connectivity, fluid mixing, etc. However, direct observation of pore-scale processes is not possible in the field. Several noninvasive imaging techniques have been developed that allow direct or spectroscopic observation of pore-scale processes within the laboratory framework. Werth et al. (2010) prepared a comprehensive review of the merits of these approaches as they apply to contaminant hydrogeology. One approach, optical imaging using ultraviolet (UV) or visual light in twodimensional (2D) model pore structures, which are etched into different substrates with transparent cover, affords many benefits, such as ease of fabrication, low cost, and fast acquisition times (Werth et al. 2010). Several other noninvasive imaging techniques include dual gamma scanning of 2D intermediate scale models, computed X-ray tomography of threedimensional (3D) columns, and nuclear magnetic resonance (NMR) measurements of fluid flow in 3D models. When fluid mixing results in the precipitation or growth of a new phase that can impact porosity and permeability, 2D micromodels, i.e., physical models of 2D pore structures etched into natural or analog materials representing idealized porous media, have been used to investigate the displacement of pore fluid by nonaqueous phase liquids (NAPL), the transport of solutes and fluid mixing, particle or colloid dynamics, and reactive transport (Figure 1). Aubin et al. (2010) reviews a variety of experimental methods for characterizing fluid mixing phenomena in 2D micromodels beyond the contaminant fate and transport context. A benefit of non-invasive imaging of 2D pore-scale models is the ability to readily correlate experimental results to numerical simulations.

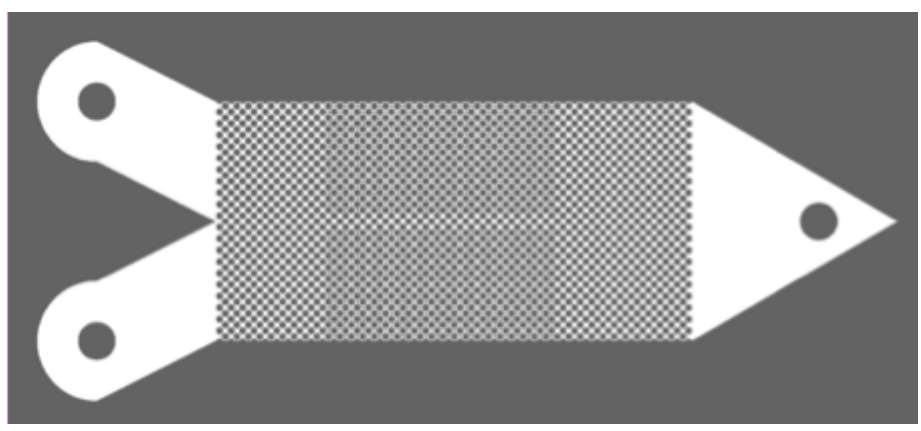

Figure 1. Pore-scale model etched in silicon. This example is designed for fluid mixing experiments with two inlets and a single outlet. The pore structure in the central region has reduced porosity to test the impact on the extent of transverse mixing. 
Numerical simulation of fluid flow and mixing through porous media at the field scale is a challenging problem due to the wide range of length scales at which important processes act and impact contaminant fate and transport. For example, contaminant absorption and reactivity on mineral surfaces occurs at the molecular scale, fluid mobility and mixing occurs at the pore scale, heterogeneity in porosity and permeability at intermediate scale, and stratigraphic boundaries can occur at meter to kilometer scale. Due to computational limitations, it is not possible to simulate all of the processes impacting field-scale phenomena using pore-scale resolution. Spatial averaging and empirical parameterization of chemical processes is commonly employed to develop a macroscopic or continuum-scale approximation (Kang et al. 2010). However, it is necessary to understand the key processes at the pore scale and develop the correct parameterization to reduce uncertainties when translated to the continuum scale models. Additionally, any theoretical or numerical approach needs a detailed understanding not only of the key processes at the pore-scale but also an accurate and realistic characterization of the structure of the porous medium (Piri and Blunt 2005).

Currently, multiple numerical approaches are used to model single-phase flow, multiphase flow, and reactive transport at the pore scale, including lattice Boltzmann modeling (LBM), smoothed particle hydrodynamics (SPH), and hybrid multiscale simulation approaches, combining computationally intensive pore-scale simulations and less computationally intense continuum-scale simulations for larger spatial areas. The strengths and weaknesses of these models have been discussed in the literature. Thus far, however, they cannot be directly compared using a common experimental data set (Kang et al. 2010; Meakin and Tartakovsky 2009).

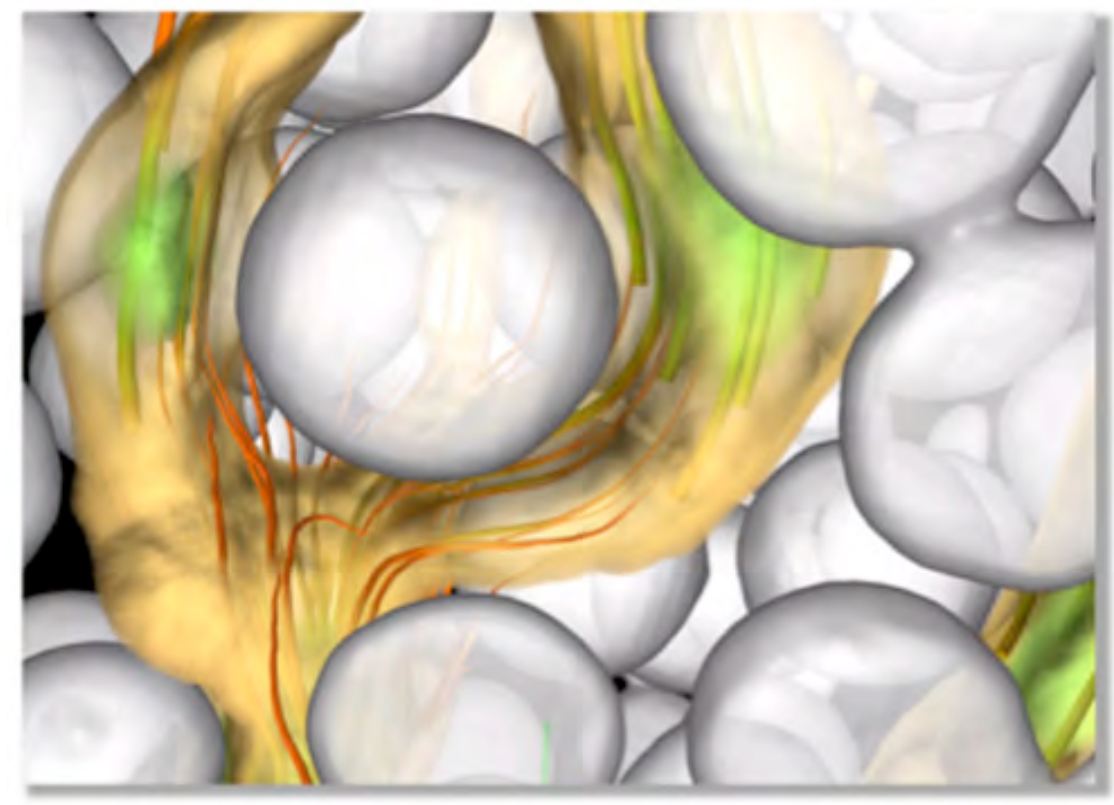

Figure 2. Zoomed-in view of a 3D visualization of pore-scale fluid flow computed using the parallel smoothed particle hydrodynamics code (Palmer et al. 2010).

Pore-scale experimental data support model validation, provide insights to field observations, and can lead to targeted and efficient computation across scales. However, there currently are no widely available experimental data sets that modelers can use to perform validation or cross-validation of the numerical simulations. Undoubtedly, there is diversity in the assumptions and numerical approaches used in these models, yet there is no data set to compare their accuracy or efficiency. A primary goal of this workshop was to bring the pore-scale experimental and modeling communities together to create a set of experimental data sets that can be used to develop new and test existing computational models, as well as generate set of challenge data sets that modelers can use to test the predictive capability of their models. By comparing the 
accuracy, efficiency, and scalability of different computational approaches to a common experimental data set, the expectation is it may lead to the development of improved models within a more collaborative environment.

\subsection{Environmental Molecular Sciences Laboratory}

The Environmental Molecular Sciences Laboratory (EMSL) is a national scientific user facility sponsored by the Department of Energy's (DOE) Office of Biological and Environmental Research that provides integrated experimental and computational resources for discovery and technological innovation. EMSL's primary research focus is environmental molecular sciences to support the DOE's mission needs. However, EMSL and its personnel also support research in the biological, chemical, physical, and computational sciences relevant to other governmental agencies and the nation.

In 1997, EMSL opened its doors to users and, over the past 15 years, has established a strong science foundation and demonstrated a robust and productive user program. Still, EMSL seeks to further focus research efforts to deliberately address national and global challenges related to energy and the environment. As a national user facility, EMSL is well positioned to focus research attention and efforts on important scientific challenges that address major societal issues. The EMSL objective is to accelerate scientific innovation and discovery by transforming how scientific research is done.

Although much of the user-proposed research conducted in EMSL involves multiple instruments and technical capabilities, there are significant additional opportunities to advance science and speed scientific progress by appropriately designed experimental and computational research efforts, advanced data integration and sharing, and the formation of research teams focused on solving important problems. Furthermore, the EMSL user program can provide a process to assist in assembling teams with the diverse expertise to address important and challenging problems, especially those in catalysis research, because of the range and particularly relevant capabilities of EMSL resources.

\subsection{EMSL Pore-scale Capabilities}

Over the past five years, EMSL has developed extensive pore-scale experimental capabilities in collaboration with Mart Oostrom and Changyong Zhang (both of PNNL) and Professor Charles Werth, University of Illinois at ChampaignUrbana. EMSL has fabrication, experimental, and modeling capabilities at the pore scale. Using recommendations from the University of Illinois, EMSL assembled a complete micromodel microfabrication capability that includes everything from silicon wafer cutters, direct-write lithography, and photomask aligners to thermal and UV nanoimprint lithography systems, a deep-reactive ion etching system, and a wafer bonder. Microfabrication facilities also are available for micromodels based on other materials such as PDMS (polydimethylsiloxane). EMSL has two inverted epifluorescent microscopes for observing pore-scale phenomena at micron-scale resolutions, as well as an inverted Raman confocal microscope for spectroscopic identification of solid phases within the micromodels.

The pore-scale facilities reside within EMSL's Subsurface Flow and Transport Laboratory. EMSL users can employ subsurface flow and transport capabilities to focus on the application of fundamental physical chemistry concepts to the study of chemical reactions in heterogeneous natural material with an emphasis on soil and subsurface systems. EMSL's approach to subsurface flow and transport studies is holistic, integrating flow cells, analytical tools, and predictive modeling capabilities to study the fate and transport of environmental contaminants, including metals, radionuclides, and chemicals.

A variety of flow cells are available to EMSL users, including column, batch, radial, wedge, and rectangular flow cells, as well as microfluidics instrumentation. Flow cells are used in coordination with high-precision, high-sensitivity analytical 
tools to generate data about sample characteristics by detecting the presence of carbon, trace metals, ions, non-volatile compounds, thermally labile chemicals, and more. EMSL users have the benefit of designing experiments using the predictive subsurface flow and transport simulator STOMP, or Subsurface Transport Over Multiple Phases (White and Oostrom 2006). Data derived from experiments using EMSL's subsurface flow and transport capabilities have further refined STOMP, which continues to increase its precision.

X-ray computed tomography (XCT) of subsurface geological field cores allows visualization of pore structure and pore connectivity at tens of microns in spatial resolution for large-diameter cores. The large size of the sample environment and the variety of X-ray targets available allows in situ experiments of fluid displacement studies, such as non-aqueous phase organic or supercritical $\mathrm{CO}_{2}\left(\mathrm{scCO}_{2}\right)$ studies. Experiments are conducted to study pore connectivity in natural rocks and sedimentary cores from field sites and provide complementary data to the pore- and intermediate-scale flow capabilities (Figure 3).

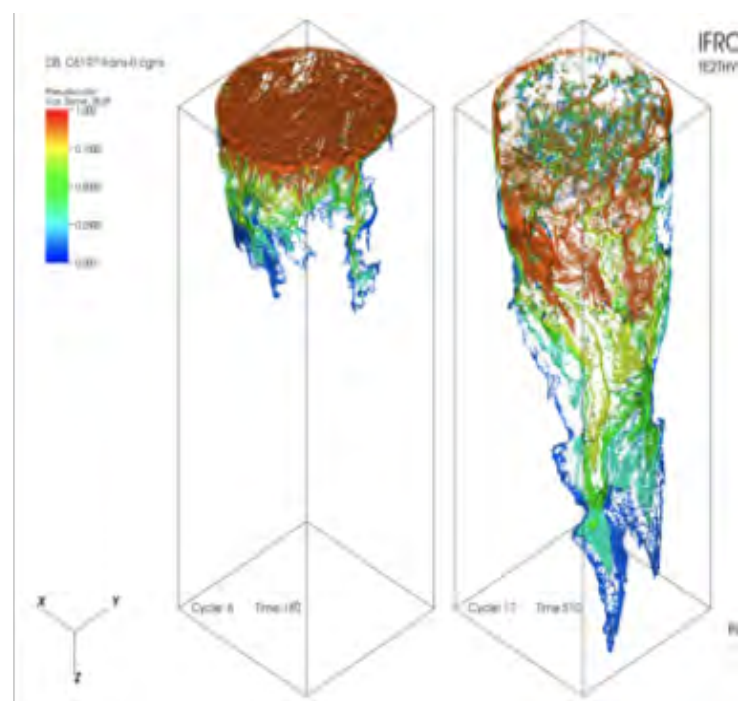

Figure 3. Flow paths in Hanford sediment core using Tethys (Transient Energy Transport Hydrodynamic Simulator) at two time points.

\subsection{Accelerating Science}

A secondary goal of this workshop was to examine how EMSL and the larger pore-scale experimental and modeling community could work together to identify fundamental research challenges and design a set of experiments at the pore scale that will speed the development of field-scale models of contaminant flow and transport with greater predictive capability and accuracy. Key experiments will be executed at EMSL, and the experimental results would be available to the modeling community to benchmark their computational approaches and share their results using an EMSL website. In this way, the results are available to the community in a more rapid fashion than possible through the traditional route of journal publication. EMSL will build and maintain a website where data sets are available to the community and the community can upload their simulations and discuss results with others. Ultimately, the results of this community effort will be published in relevant journals and presented at national meetings. This community- or team-based approach will accelerate the improvement in field-scale models. 


\subsection{Workshop Objectives}

The high-level objective of this workshop is to accelerate development of field-scale subsurface fate and transport models with increased predictive accuracy by designing specific pore-scale experiments that modelers can use to test and validate their simulations. The workshop also served to make the community aware of EMSL experimental and computational capabilities that they could use to further their research. The workshop participants, an assembly of multi-institutional teams with diverse expertise, would be able to address important problems or challenges in a way that could significantly accelerate progress.

The participants in the workshop were asked to answer three questions:

1. What are the numerical simulation and experimental challenges that face the community?

2. What are the experimental data sets that can be developed to address these challenges?

3. What are the needed experimental capabilities to meet these challenges?

The workshop included overview presentations by invited speakers that described the current challenges impeding further progress and short presentations by the participants showcasing their work (both experimental and numerical simulation). Workshop participants included researchers from academic institutions, national laboratories, EMSL staff members, and PNNL staff members with experimental and modeling expertise and interests at the pore scale. The invited speakers included recognized thought leaders in experimental and computational pore-scale flow and transport. In addition to participating in the discussion, the invited speakers assembled their initial thoughts on important topics and critical capabilities prior to the workshop. The workshop agenda and list of participants can be found in Appendix A and Appendix B, respectively. The discussion sessions focused on developing sets of foundational pore-scale experiments that underlie the more complex phenomena that are important at the field scale. At the workshop's conclusion, two working groups, representing fluid displacement phenomena and transverse reactive mixing, outlined the challenges and initial thoughts on possible experimental plans in these fundamental research areas. A summary of the discussions of important research areas, needed capabilities, and recommendations for the proposed experimental plan is provided in Sections 3- 5 . 


\subsection{Important Research Directions}

The workshop began with succinct overviews, provided by Professor Michael Celia and Drs. Tim Scheibe and Qinjun Kang, on the state-of-the art in numerical simulation of pore-scale phenomena. After this introduction, participants in the workshop were provided the opportunity to present their initial thoughts on important areas. The next set of invited talks included both numerical modeling and experimental overviews by Professors Markus Hilpert and Laura Pyrak-Nolte and Dr. Alex Tartakovsky. Workshop participants were invited to discuss their response to the suggested challenges and approaches. The third group of invited speakers presented the state-of-the art in pore-scale experiments. These speakers included Professors Werth and Dorthe Wildenschild. Many attendees also volunteered to present their own research efforts and shared their insights on the dominant challenges to pore-scale research. After lively discussions about the most relevant and impactful issues, the workshop concluded by having the participants form two working groups: one focused on reactive transport and the other on multiphase flow. Each working group presented a summary of the issues and proposed initial concepts for experiments deemed important for advancing pore-scale modeling.

Although there was diversity in opinions during the workshop discussions, there also was consensus in many areas. Some of the reoccurring themes that resonated with the participants include the need for pore-scale experiments to extract information actually useful for large-scale numerical simulations of field-scale phenomena, the ability to design pore-scale experiments to identify key processes that impact field-scale phenomena, and the importance of authentic parameterization of key pore-scale phenomena in continuum-scale models.

Beyond the overarching themes, three important research directions were identified: 1) fluid mixing and reactive transport phenomena, 2) multiphase flow and fluid displacement phenomena, and 3) numerical simulations. Finally, several contributed presentations demonstrated how the concepts intrinsic to contaminant fate and transport in the subsurface had application beyond this field. These research directions and important questions are summarized in the following subsections.

\subsection{Fluid Mixing/Reactive Transport}

Fluid mixing underlies many phenomena at the pore scale, such transverse mixing, flow focusing, mineral precipitation and dissolution, formation of microbial growth, and biofilms that impact fluid movement at intermediate and field scale. Understanding these phenomena is necessary for predicting contaminant fate and transport and the design of contaminant remediation strategies. During the workshop, several important topical areas were identified where new or advanced understanding of fluid mixing would have high impact, including:

- Desire to uncouple mass transfer limitations from precipitation reaction rate constraints

- The effects of flow and mixing on the precipitation rates of different minerals are not clear

- Need for more experiments under the conditions of high advection/diffusion ratio or high Péclet numbers

- The unclear effect of mineral precipitation on diffusive mixing

- What is the relationship between phenomena observed in 2D and 3D models?

- How does variability in parameters, such as temperature, pressure, surface roughness, surface wettability, and surface chemical composition, impact 2D pore-scale experimental studies?

- Mineral release during dissolution is a largely unexplored phenomenon, and it is not clear how it affects mineral stability and risk. 
- What is the impact of gravity on 2D pore models of precipitation?

\subsection{Multiphase Flow/Fluid Displacement Phenomena}

Multiphase flow and/or fluid displacement phenomena include processes such as hysteresis, snap-off, interfacial area, wetting and non-wetting surfaces and fluids, and percolating and non-percolating fluid fractions. These phenomena are necessary to understand when fluids with contrasting physical properties are in contact. For example, these situations would include the interface between saturated and unsaturated sediments, the subsurface migration of nonaqueous phase liquids, and injection of $\mathrm{scCO}_{2}$. Pore-scale models allow us to extract information about the interface between fluids through measurement of contact angles, interfacial area, and hysteresis. Several of these important challenges were identified at the workshop and include:

- Experimental imperfections can adversely impact the type of visible displacement phenomena. Can we design experiments that are not so affected by experimental artifacts?

- How do we define and measure an average pressure in displacement experiments?

- Does the height of 2D models impact experimental results?

- Are 2D results relevant to 3D flow?

- Can we distinguish percolating from non-percolating phases in 2D and 3D models? A connected versus disconnected domain depends on the scale of the observation. For example, a connected blob at $5 \mathrm{~cm}$ can be a disconnected blob at $10 \mathrm{~cm}$.

- Under what conditions are measurements of interfacial area relevant to predicting displacement behavior?

- Not all the hysteretic behavior can be derived from contact angle measurements. Can the competing contributions to hysteretic behavior from topological complexity, physical-sorption, films, etc., be resolved?

- Do thin fluid films exert an elastic force that is not currently recognized in multiphase flow experiments?

- We need to be able to predict snap-off behavior in drainage and imbibition experiments involving $\mathrm{scCO}_{2}$.

- Higher resolution computed tomography is essential for 3D imaging of fluid-grain interfaces.

\subsection{Numerical Simulations}

There are multiple challenges in pore-scale modeling beyond translating pore-scale processes to the continuum scale. Some of these challenges result from multiple coupled processes and complex morphology of porous media. For multiphase flow interface (or contact line between phases) using classical hydrodynamic approaches, the numerical description becomes singular in the vicinity of the contact line. Precipitation and dissolution creates an additional dimension to numerical models because the already complex pore morphology and connectivity changes as a function of time. The growth of biomass within porous media creates similar complexity. Dentz et al. (2011) provided a review of some of the formulations for transitioning between pore to Darcy or continuum scale.

Molecular diffusive processes largely control fluid mixing in micromodels because the flow rates are maintained within the laminar flow regime. Numerical simulations of the mixing phenomena at the pore-scale are often conducted using LBM because it can readily accommodate movement of phase boundaries and changing reactive species. However, additional approaches have been developed. Several computational frameworks were presented at the workshop, including the continuum models such as STOMP and PFLOTRAN and pore-scale models such as SPH. Other groups take a hybrid 
multiscale simulation approach between micro pore scale that are computationally intensive and a macro pore-scale approach, which is less computationally intense and covers a larger spatial area. LBM methods were used by other groups to perform flow simulations at the pore scales to create the velocity fields. Then, they used PFLOTRAN with the resulting velocity fields to do the reactive transport simulations (Figure 4). Key challenges for numerical simulations identified during the workshop include:

- What is the appropriate level of complexity to bring to transport modeling when going from the pore scale to continuum scale? Are we limited by computational power or fundamental understanding?

- Numerical simulations of pore-scale phenomena should include and report the simulation error and sensitivity analysis. This is not commonly reported in the literature.

- Using Richardson's Extrapolation, which is a sequence acceleration method used to speed the rate convergence of an iterative sequence (such as those used in LBM), may only be applicable for linear equations.

- Are there better, obvious ways to write continuum models?

- Computational models that can update grain geometry and porosity changes due to mineral precipitation and dissolution are needed.

- Computational models that predict mineral dissolution as a result of reduced fluid mixing due to mineral precipitation and changes in fluid compositions are needed.

- What is the best approach for modeling complex experimental systems that include mineral precipitation or biofilm growth?

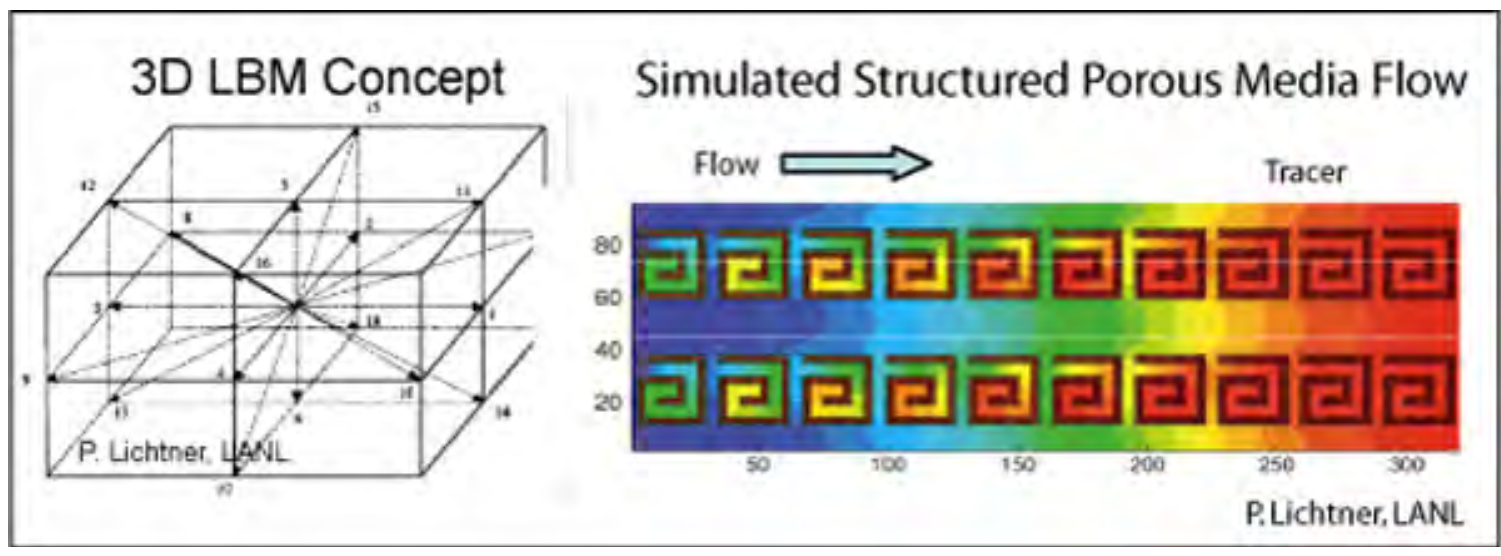

Figure 4. Representation of LBM volume (left) and example of trace flow using PFLOTRAN (right). From www.esd.lbl.gov/research/projects/ersp/generalinfo/modeling.html 


\subsection{Other Opportunities for Advancing Fundamental Understanding}

In addition to addressing important topics and identified challenges in fluid mixing and fluid displacement, significant advances in understanding may be achieved in other application areas. The workshop participants noted several opportunities for advancing pore-scale research, which seemed particularly well matched to EMSL's expertise and capabilities. Those opportunities include:

- Can the coupled mineralization (i.e., carbonization) and structural evolution of the pore structure of soil in the terrestrial ecosystem be modeled in an analogous way to other pore-scale subsurface phenomena?

- Can pore network models be used to understand how increased pressure or changes in permeability or porosity impact the injection of $\mathrm{scCO}_{2}$ into subsurface?

- Existing pore-scale models of the injection of $\mathrm{scCO}_{2}$ have not paid sufficient attention to the geochemistry, particularly for injection into carbonate rocks. How and when are the geochemical reactions important?

- Can pore-scale computational models be used to understand the growth of biofilms in porous networks, the movement of rising bubbles in fluids, or formation and migration of droplets?

- There are many challenges in modeling two-phase flow and reactive transport in fractured rocks, including:

- Nonlinear feedbacks in both space and time

- Strong spatial fluctuations or heterogeneity

- Long-term transient effects far from equilibrium. 


\subsection{Necessary Capabilities}

In many of the talks and discussions regarding the diversity of pore-scale models, experimental and collaboration tools that could be used to significantly advance pore-scale science was addressed. Characteristics of required capabilities and capability challenges are summarized in the following subsections. In addition, there were repeated discussions regarding the nature of the relationship between phenomena observed in 2D experimental models and analogous experiments in 3D. There was concern that some of the cyclic precipitation and dissolution reactions observed in 2D pore-scale models may not occur in 3D pore-scale models. As a result, there was a desire to design quasi-3D pore-scale models to test the continuity between 2D and 3D experimental observations.

\subsection{Pore-scale Models}

- 2D models

- Develop better fabrication techniques to generate true 2D flow models with smooth, vertical pillars and sharp transitions to base and top

- Need to develop greater variety of in situ sensors for $\mathrm{pO}_{2}, \mathrm{pH}$, and chemical concentration, as well as other chemically relevant phenomena in 4D (spatially and temporally)

- Need to develop methods for assessing the volume and density of precipitates formed in fluid-mixing experiments

- Need to develop method for fabricating micron-size "fractures" in 2D micromodels

- Need to identify mineral systems with a range of favorable kinetic precipitation rates.

- 3D models

- Develop photolithographic methods for generation of highly regular 3D pore structures, such as those produced for 2D flow models

- Development of more realistic 3D models

- In situ intermediate-scale flow capability at high pressure and temperature for $\mathrm{scCO}_{2}$ experiments

- Development of sensors-"displacement capacitors" to measure in 3D networks.

\subsection{Specific Types of Instruments}

Although some instruments are commercially available, they are not routinely found in academic institutions. As such, specific instruments or needed advances in instrumental capabilities that would complement EMSL's existing pore-scale fabrication and experimental, intermediate-scale, and XCT capabilities were recommended.

- Index of refraction matched column experiments for in situ visualization of fluid flow in three dimensions. If non-transparent media are used to pack the column, optical or laser imaging of fluid flow in columns generally is limited to the outer surface. However, if transparent media are used and the choice of fluid matches the index of refraction of the media, optical methods can be used to construct 3D images of fluid flow in the column.

- Micro X-ray computed tomography $(\boldsymbol{\mu X C T )}$ ). Standard XCT of subsurface geological field cores allows visualization of pore structure and pore connectivity at the tens of microns in spatial resolution for large-diameter cores. However, some pore-scale experiments, such as measurements of interfacial area, require at least micron 
resolution. These types of experiments are possible using $\mu \mathrm{XCT}$ instruments that have micron-sized beam spot size. A disadvantage is the core or column diameter also must be smaller than the standard geologic core.

- Magnetic resonance imaging (MRI). MRI instrumentation has been used to characterize porous media columns and subsurface geologic cores to determine grain size, porosity, fluid distribution and saturation, fluid flow paths and velocity, and interfacial area in multiphase experiments. Because MRI can generate 2D or 3D images, it is complementary to XCT imaging. The main advantage of MRI is its ability to measure flow paths and velocity. MRI's main disadvantage is its sensitivity to ferrous-bearing sediments. Thus, it typically is used with limited natural geologic materials or with artificial porous media (Werth et al. 2010). Secondary considerations are the initial expense and expertise needed to operate and analyze the data. These two latter considerations would result in MRI capabilities uncommon in academic institutions.

\subsection{Collaboration Tools}

Some considerations to enhance collaborations included:

- Mechanism to access experimental data sets that can be used to validate computational models

- Repository for well-characterized experimental results

- Visualization tools to compare simulations against experiment

- Forum to share and discuss simulation results with community

- Access to computational resources. 


\subsection{Overall Recommendations}

Three general recommendations were voiced repeatedly during the workshop regarding how the EMSL's pore-scale modeling should be focused. These recommendations include the importance of keeping the experiments simple and fundamental to avoid highly complex behavior and to focus initially on fluid mixing and fluid displacement experiments. Many of the workshop participants agreed that it was difficult to conduct such fundamental research under their current research programs. As such, this effort would be advantageous in providing insights to basic pore-scale behavior.

\section{Focus on fluid mixing and fluid displacement experiments}

There was good agreement at the workshop to focus initial efforts on fluid mixing and fluid displacement experiments. Two break-out groups led by Professors Werth and Celia discussed the challenges in these two areas. The following is a brief summary of their discussions.

\subsection{Reactive Transport-Fluid Mixing}

In several different discussions, workshop participants indicated it is necessary to understand flow, mixing, chemical gradients, and reactions on surfaces. A good approach is to start simple and gradually build more complex problems. One example would start with a system consisting of only fluid mixing without reactions then increase the complexity by adding reaction chemistry. The participants indicated the need to: 1) study chemical reactions that are instantaneous and rate-limited aqueous reactions as opposed to precipitation reactions that are complicated due to the change in pore geometry and impact of precipitates on flow and mixing and 2) compare 2D and 3D systems.

Another suggested research topic was to investigate if it is possible for mineral precipitation systems to uncouple the reaction kinetics and phase reactions. One initial starting point might be $\mathrm{CaCO}_{3}$, which has been worked with extensively. An example of a more detailed study area might be to verify experimentally where calcite forms relative to other $\mathrm{CaCO}_{3}$ minerals, depending on the chemical gradient.

The group also discussed increasing the heterogeneity of the system and looking at it in a flow-through system. Example analyses included:

- How it seeds and grows is different in flow-through versus batch system. Can they be matched better?

- Can rates from a batched system be modeled in a flow cell?

- People are looking at complicated reactions. Instead, they might look at very simple systems heterogeneous reactions - can they be matched using known kinetics?

In comparing 2-D versus 3-D, the group also had distinct observations:

- Can we match the chemistry and surfaces in both 2D and 3D?

- If we review aqueous space reactions, we should be able to look at the models and parameters and model them with only changes to the boundary conditions.

- Can we use the model formulation for the boundary conditions? 


\subsection{Displacement-Multiphase Flow}

The effects of anisotropy on capillary pressure-fluid saturation and relative permeability-fluid saturation relationships are critical to understanding multiphase flow and displacement. The group indicated an experimental campaign should include:

- Layered heterogeneity

- Broken layers

- Anisotropic particle shapes and pore sizes.

Professor Celia noted the group saw some benefit in having experiments focused on snap-off and dynamic effects. Other analysis areas included:

- Keeping track of what fraction of each phase is percolating or non-percolating (connected/not connected)

- Try to have similar experiments in 2D and 3D to see the impact of dimensionality

- Dynamic capillary pressure and contact angle, i.e., can you measure dynamic contact angle?

- Experiments focused on supersaturation and precipitation/dissolution.

\subsection{Role for EMSL in Pore-scale Modeling and Team Research Success}

In several different discussions, workshop participants indicated there were multiple ways that provided important expertise and capabilities that could be used to enable significant advances in pore-scale research. These characteristics include:

- Access to microfabrication capability expertise for custom pore-scale models

- Ability to generate high-quality data sets for simulation community

- Ability to store, share, and maintain experimental data sets with access to the pore-scale community. For example, several researchers had access to data sets that they would be willing to make available to the broader community. EMSL could be the repository for these contributed data sets.

- Ability to host or coordinate virtual meetings

- The capability to maintain unique instruments operating under extreme or in situ conditions that would difficult to replicate at universities

- The ability to provide long-term continuity to the research direction

- Mentoring young researchers by world-quality experts operating state-of-the-art instrumentation.

Other specific focus items include:

EMSL can help collaborative team formation and demonstrate the impacts of doing science in a collaborative way. The workshop advisors thought it was appropriate that EMSL, as a user facility, lead the formation of a pore-scale research team composed of both experimental and computational researchers who define common research challenges that need to be addressed. 
EMSL needs to develop a long-term collaborative proposal process. The normal mode of relatively short-term user proposals is not a model that affords significant advances in areas of high complexity. EMSL needs to develop a mechanism that allows longer-term collaboration in specific target areas.

Data sharing is vital. The ability to share data and information at all levels and various stages of research is essential to accelerating the rate of research progress. A new website and the MyEMSL platform can provide some basis for this. However, it likely will require expansion and development of standard data formats and new visualization tools. 


\subsection{References}

Aubin J, M Ferrando and V Jiricny. 2010. "Current methods for characterising mixing and flow in microchannels." Chemical Engineering Science 65(6):2065-2093.

Dentz M, T Le Borgne, A Englert and B Bijeljic. 2011. "Mixing, spreading and reaction in heterogeneous media: A brief review." Journal of Contaminant Hydrology 120-121:1-17.

DOE - U.S. Department of Energy. 2010. "Complex Systems Science for Subsurface Fate and Transport: Report from the August 2009 Workshop.” DOE/SC-0123, U.S. Department of Energy Office of Science, Washington D.C.

Kang Q, PC Lichtner, and DR Janecky. 2010. "Lattice Boltzmann Method for Reacting Flows in Porous Media." Advances in Applied Mathematics and Mechanics 2(5):545-563.

Meakin P and AM Tartakovksy. 2009. "Modeling and simulation of pore-scale multiphase fluid flow and reactive transport in fractured and porous media." Reviews of Geophysics 47:RG3002. DOI: 10.1029/2008RG000263.

Palmer BJ, V Gurumoorthi, AM Tartakovsky, and TD Scheibe. 2010. "A Component-based Framework for Smoothed Particle Hydrodynamics Simulations of Reactive Fluid Flow in Porous Media." International Journal of High Performance Computing Applications 24(2):228-239.

Piri M and MJ Blunt. 2005. "Three-dimensional mixed-wet random pore-scale network modeling of two and three-phase flow in porous media. II. Results.” Physical Review E 71(2):026302.

Werth CJ, C Zhang, ML Brusseau, M Oostrom, and T Baumann. 2010. “A review of non-invasive methods and applications in contaminant hydrology research.” Journal of Contaminant Hydrology 113(1-4):1-24.

White MD and M Oostrom. 2006. STOMP Subsurface Transport Over Multiple Phases, Version 4.0, User's Guide. PNNL-15782, Pacific Northwest National Laboratory, Richland, Washington. 


\section{Appendix A: Agenda}

\section{EMSL Pore Scale Modeling Challenge/Workshop}

\begin{tabular}{|c|c|c|}
\hline August 9, 2011 & Invited Speaker Agenda & 然 \\
\hline $8: 30-8: 50$ & $\begin{array}{l}\text { Michael Celia, } \\
\text { Princeton }\end{array}$ & $\begin{array}{l}\text { Testing Continuum-scale Theories for Two-phase Flow usin: } \\
\text { Pore-scale Network Models. }\end{array}$ \\
\hline $8: 50-9: 10$ & $\begin{array}{l}\text { Tim Scheibe, Pacific } \\
\text { Northwest National } \\
\text { Laboratory }\end{array}$ & $\begin{array}{l}\text { Hybrid Multiscale Modeling: Coupled Pore- and Darcy- } \\
\text { scale Models of Reactive Transport. }\end{array}$ \\
\hline $9: 10-9: 30$ & $\begin{array}{l}\text { Qinjun Kang, Los } \\
\text { Alamos National } \\
\text { Laboratory }\end{array}$ & $\begin{array}{l}\text { Lattice Boltzmann Modeling of Multiphase Flow and } \\
\text { Reactive Transport at the Pore scale and its Coupling with } \\
\text { PFLOTRAN. }\end{array}$ \\
\hline $2: 00-2: 20$ & $\begin{array}{l}\text { Markus Hilpert, } \\
\text { Johns Hopkins } \\
\text { University }\end{array}$ & $\begin{array}{l}\text { Lattice-Boltzmann Modeling of Pore-scale Flow and } \\
\text { Transport Processes in Porous Media. }\end{array}$ \\
\hline $2: 20-2: 40$ & $\begin{array}{l}\text { Laura Pyrak-Nolte, } \\
\text { Purdue University }\end{array}$ & Interfacial Areas and Films in Micro-models. \\
\hline $2: 40-3: 00$ & $\begin{array}{l}\text { Alex Tartakovsky, } \\
\text { Pacific Northwest } \\
\text { National Laboratory }\end{array}$ & $\begin{array}{l}\text { Pore-scale Smoothed Particle Hydrodynamics Model for } \\
\text { Multiphase Flow and Reactive Transport. }\end{array}$ \\
\hline August 10, 2011 & vited Speaker Agenda & \\
\hline $8: 00-8: 20$ & $\begin{array}{l}\text { Charles Werth, } \\
\text { University of Illinois }\end{array}$ & $\begin{array}{l}\text { Predicting Particle Flow, Mixing, and Reaction at the Pore- } \\
\text { scale: The Need for Pore-scale Data Sets to Support } \\
\text { Increasingly Complex Modeling Efforts. }\end{array}$ \\
\hline $8: 20-8: 40$ & $\begin{array}{l}\text { Dorthe } \\
\text { Wildenschild, } \\
\text { Oregon State } \\
\text { University }\end{array}$ & $\begin{array}{l}\text { X-ray Computed Microtomography: Opportunities and } \\
\text { Limitations for Porous Media Characterization and Process } \\
\text { Quantification. }\end{array}$ \\
\hline 8:40-9:00 & $\begin{array}{l}\text { Changyong Zhang, } \\
\text { Pacific Northwest } \\
\text { National Laboratory }\end{array}$ & $\begin{array}{l}\text { Pore-scale Experimental Study of Miscible / Immiscible } \\
\text { Flow Coupled with Biogeochemical Reactions Relevant to } \\
\text { Contaminant Transport and Carbon Sequestration in the } \\
\text { Subsurface. }\end{array}$ \\
\hline
\end{tabular}


August 9-10, 2011

\begin{tabular}{|c|c|c|}
\hline August 9, 2011 & Participant Presentations & \\
\hline $9: 30-9: 45$ & $\begin{array}{l}\text { Ryan Kelly, Pacific Northwest } \\
\text { National Laboratory }\end{array}$ & Overview of EMSL Microfabrication Capabilities. \\
\hline $9: 45-10: 00$ & Florian Doster, Princeton & $\begin{array}{l}\text { Hydrodynamic Properties of Percolating and Non-percolating } \\
\text { Fluids: Are they Crucial for our Understanding of Macroscopic } \\
\text { Hysteresis? }\end{array}$ \\
\hline 10:00-10:15 & Thomas Elliot, Princeton & Inundation and Pedogenesis of Petrocalcic Soil. \\
\hline $10: 15-10: 30$ & Juan Nogues, Princeton & $\begin{array}{l}\text { Investigations in Dissolution and Precipitation of Carbonate Rocks } \\
\text { using Pore Network Models. }\end{array}$ \\
\hline $10: 30-10: 45$ & $\begin{array}{l}\text { Guoping Tang, Oak Ridge } \\
\text { National Laboratory }\end{array}$ & Challenges in Pore-scale Modeling of Structured Soils. \\
\hline $10: 45-11: 00$ & $\begin{array}{l}\text { Hongkyu Yoon, Sandia } \\
\text { National Laboratory }\end{array}$ & $\begin{array}{l}\text { Pre-scale Simulation of Mixing-induced Calcium Carbonate } \\
\text { Precipitation and Dissolution in a Microfluidic Pore Network. }\end{array}$ \\
\hline $2: 00-2: 15$ & $\begin{array}{l}\text { Wen Deng, University of } \\
\text { Texas }\end{array}$ & $\begin{array}{l}\text { Snap-off of Supercritical } \mathrm{CO}_{2} \text { within Circular and Noncircular } \\
\text { Pores. }\end{array}$ \\
\hline $2: 15-2: 30$ & $\begin{array}{l}\text { Rinaldo Gonzalez Galdamez, } \\
\text { Florida International } \\
\text { University }\end{array}$ & $\begin{array}{l}\text { Lattice Boltzmann Modeling for Multiphase Flows: Rising Bubble } \\
\text { Simulations and Beyond. }\end{array}$ \\
\hline $2: 30-2: 45$ & $\begin{array}{l}\text { Hai Huang, Idaho National } \\
\text { Laboratory }\end{array}$ & $\begin{array}{l}\text { Complex Dynamics of Multiphase Flow and Reactive Transport } \\
\text { Processes in Pores and Fractures. }\end{array}$ \\
\hline $2: 45-3: 00$ & $\begin{array}{l}\text { Hun Bok Jung, Pacific } \\
\text { Northwest National } \\
\text { Laboratory }\end{array}$ & $\begin{array}{l}\text { Carbonation of Wellbore Cement under Carbon Sequestration } \\
\text { Condition. }\end{array}$ \\
\hline $3: 00-3: 15$ & $\begin{array}{l}\text { Haluk Resat, Pacific } \\
\text { Northwest National } \\
\text { Laboratory }\end{array}$ & Challenges in Multiscale Modeling of Bacterial Dynamics. \\
\hline $3: 15-3: 30$ & $\begin{array}{l}\text { Tianyu Zhang, Montana State } \\
\text { University }\end{array}$ & $\begin{array}{l}\text { Mathematical Model of Biofilm Induced Calcite Precipitation at } \\
\text { the Pore-scale. }\end{array}$ \\
\hline August 10, 2011 & Part & \\
\hline $9: 00-9: 15$ & $\begin{array}{l}\text { Robin Gerlach, Montana State } \\
\text { University }\end{array}$ & $\begin{array}{l}\text { Investigating and Modeling the Influence of Biofilm Formation } \\
\text { and Biofilm-mediated Mineral Formation on Reactive Transport in } \\
\text { Porous Media. }\end{array}$ \\
\hline $9: 15-9: 30$ & $\begin{array}{l}\text { Teamrat Ghezzehei, } \\
\text { University of California, } \\
\text { Merced }\end{array}$ & $\begin{array}{l}\text { Linking Evolution of Sub-pore Scale Chemical/Morphological } \\
\text { Heterogeneity with Changes in Macroscopic Hydraulic Properties. }\end{array}$ \\
\hline $9: 30-9: 45$ & $\begin{array}{l}\text { George Redden, Idaho } \\
\text { National Laboratory }\end{array}$ & $\begin{array}{l}\text { Mixing/Reaction Fronts in Porous Media: Poor Mixing }=\text { Bad } \\
\text { Behavior. }\end{array}$ \\
\hline $9: 45-10: 00$ & $\begin{array}{l}\text { Marshal Richmond, Pacific } \\
\text { Northwest National } \\
\text { Laboratory }\end{array}$ & $\begin{array}{l}\text { Simulation of Pore-scale Flow and Tracer Transport in a Column- } \\
\text { scale Core Sample. }\end{array}$ \\
\hline 10:00-10:15 & $\begin{array}{l}\text { Kenton Rod, Pacific } \\
\text { Northwest National } \\
\text { Laboratory }\end{array}$ & $\begin{array}{l}\text { Challenges with Measuring Diffusion into Micro-channels using } \\
\text { Micro-fluidic Devices. }\end{array}$ \\
\hline $10: 15-10: 30$ & $\begin{array}{l}\text { Guohui Wang, Pacific } \\
\text { Northwest National } \\
\text { Laboratory }\end{array}$ & $\begin{array}{l}\text { Radionuclide Immobilization and Flow Path Modifications by } \\
\text { Dissolution and Secondary Precipitates. }\end{array}$ \\
\hline
\end{tabular}




\section{Appendix B: Meeting Participants}

Advisory Panel

Michael Celia

Princeton University

Markus Hilpert

Johns Hopkins University

Qinjun Kang

Los Alamos National Laboratory

Laura Pyrak-Nolte

Purdue University

Tim Scheibe

PNNL

Alex Tartakovsky

PNNL

Charlie Werth

University of Illinois at Urbana-Champaign

Dorthe Wildenschild

Oregon State University

Changyong Zhang

PNNL

Registered Attendees

Stephen Bialkowski

Utah State University

Teamrat Ghezzehei

University of California, Merced

Guoping Tang

Oak Ridge National Laboratory

Florian Doster

Princeton University

Jitendra Kumar

Oak Ridge National Laboratory
Rishi Parashar

Desert Research Institute

Robin Gerlach

Montana State University

Hongkyu Yoon

Sandia National Laboratories

George Redden

Idaho National Laboratory

Tianyu Zhang

Montana State University

Hai Huang

Idaho National Laboratory

Juan Nogues

Princeton University

Wen Deng

The University of Texas

Haluk Resat

Washington State University

PNNL

Nancy Hess-workshop organizer

Mart Oostrom-workshop organizer

Kenton Rod

Don Baer

Ryan Kelly

Wooyong Um

Guohui Wang

Marshall Richmond

Dave Rector

Mark Stewart

Hun Bok Jung

Meeting Support and Administration

Charity Plata 


\section{Appendix C: Sample Invitation Letter}

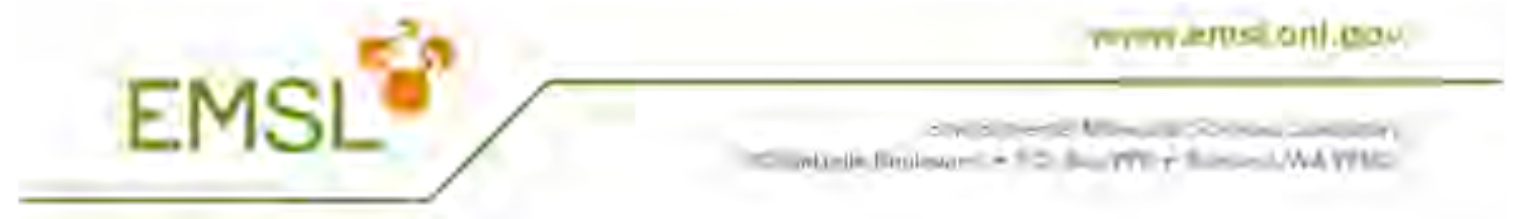

Dear Participant,

Please find attached an informational flyer regarding an upcoming pore-scale modeling workshop that we would hope that you would attend as an invited speaker. EMSL is hosting a 2 day workshop at Pacific Northwest National Laboratory in Richland WA during the week of August $8^{\text {th }}$. Because of your contributions in this area we would be delighted if you would consider attending and presenting an invited talk about your perspective on the current challenges in pore scale modeling and your thoughts on some initial pore-scale experiments run that would serve to test and validate different numerical modeling approaches and accelerate the development of reactive transport models.

We will finalize the dates as soon as hear back from other invited speakers so please let us know of your availability during the week of Aug $8^{\text {th }}$. If you can accept we will need to complete a workshop agreement to reimburse you for your travel and lodging costs. Please feel free to contact one of us if you have any questions regarding the scope of the workshop.

Best regards,

Nancy Hess and Mart Oostrom

Nancy J. Hess

Science Lead

Geochemistry, Biogeochemistry and Subsurface Science

EMSL

509-371-6385

nancy.hess@pnl.gov

Mart Oostrom

EMSL Wiley Fellow, Staff Scientist

Hydrology

PNNL

509-372-6044

mart.oostrom@pnl.gov

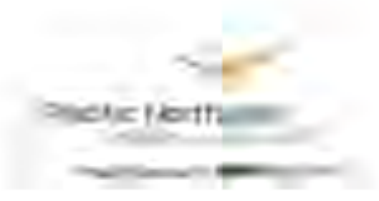




\section{Appendix D: Sample Flyer}

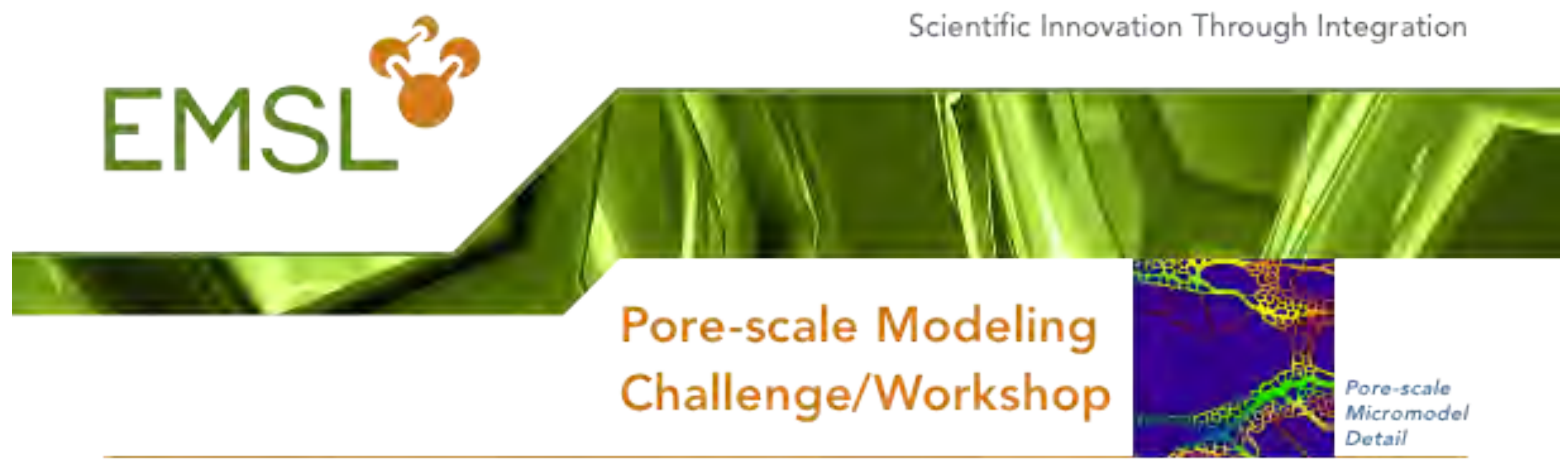

Developing predictive flow and transport models at the pore scale is a challenge common to diverse science areas Increasingly, it has become more important in subsurface research due to its relevance to contaminant and colloidal transport, non-aqueous phase liquid (NAPL) dissolution, and interest in deep sequestration of $\mathrm{CO}$

Currently, several independent research groups are developing numerical simulations of flow and reactive transport at the pore scake without experimental data sets to validate the models.

These numerical models use a variety of computational approaches, and each has strengths in areas such as accuracy, computational speed, or scalability. Because of different numerical approaches, there is a benefit in benchmarking these models against a common experimental data set. Such a benchmark challenge highlights relative strengths of each approach and serves to accelerate progress in the field.

At the Pore-scale Modeling Challenge/Workshop, modeling groups will define a "learning set" of mutually beneficial pore-scale experimental studies to calibrate numerical models and a "challenge set" designed to numerically predict results without knowing experimental result. Micromodels would be fabricated and flow experiments conducted using EMSL's new Microfabrication Capability in tandem with EMSL's integrated subsurface flow and transport capabilities to focus on fundamental concepts, from pre-experiment modeling to hydraulic characterization, analytical chemistry, numerical modeling, and analysis. Challenge set results, a comparison of the simulation to experiment, will be reportod in a journal publication and national meetings
The workshop also will feature invited speakers discussing the current state of knowledge and concepts for initial benchmarking experiments and provide a forum to refine pore-scale experiments and define rules for a benchmarking challenge. Prospective experimental systems include diffusion in pore networks; multiphase systems, such as oil-water, water-air, mineral precipitation, and microbial growth; and colloidal transport.

\section{INVITED SPEAKERS INCLUDE:}

$$
\begin{aligned}
& \text { " Michael Celia, Princeton University } \\
& \text { " Markus Hilpert, Johns Hopkins University } \\
& \text { " } \quad \text { Laura Pyrak-Nolte, Purdue University } \\
& \text { " Timothy Scheibe, PNNL } \\
& \text { " Alexandre Tartakovsky, PNNL } \\
& \text { " Charles Werth, University of Illinois } \\
& \text { " Dorthe Wildenschild, Oregon State University }
\end{aligned}
$$

\section{WORKSHOP ORGANIZERS:}

For information regarding EMSLis Pore-scale Modeling Challenge/Workshop, contact:

Nancy Hess - nancy.hessepnl.gow

Mart Oostrom - mart.oostrom®pnl.gov

\section{August 9-10, 2011}

Environmental Molecular Sciences Laboratory

Pacifie Northwest

National Laboratory Richland, Washington

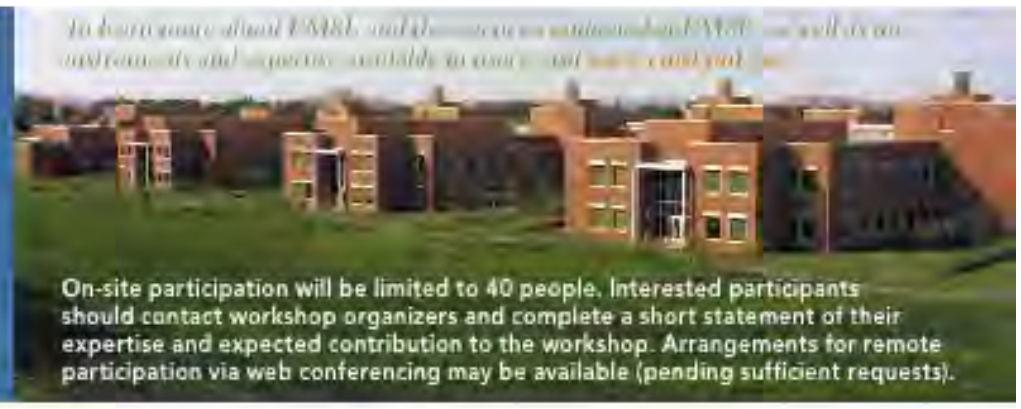

